Celal Bayar University Journal of Science

\title{
Production of Chlorella sp. in a Designed Photobioreactor
}

\author{
Büşra Ak ${ }^{1}$, Eylem Atak ${ }^{1}$, Merve Deniz $\mathrm{Köse}^{2 *}$ and Oguz Bayraktar ${ }^{2}$ \\ ${ }^{1}$ Ege University, Department of Bioengineering, Bornova, İzmir, Turkey \\ ${ }^{2}$ Ege University, Department of Chemical Engineering, Bornova, İzmir, Turkey \\ *mervedenizkose@gmail.com
}

Received: 6 February 2019

Accepted: 12 December 2019

DOI: $10.18466 /$ cbayarfbe. 523332

\begin{abstract}
Microalgae are photosynthetic microorganisms that are recently grown to produce biomass for food, pharmaceutical, dye, and bioenergy industries. Microalgae are the carbon source found in crude oil and natural gas. Over the years, there have been several advances in the design and operation of closed photobioreactors for microalgal cultures based on new reactor geometries as well as optimized aeration and mixing strategies. Closed photobioreactors ensure heat control, and high productivity through effective use of high-intensity light and prevent contamination in microalgae production. One of the most important factors that control cell growth in a photobioreactor is light availability. In this study, the cultivation of Chlorella sp., as microalgae were performed in a specially designed photobioreactor for productivity analysis and pigment capacity analysis. The applied light energy was kept constant while applying either continuous or intermittent lighting during the growth of microalgae. The cultivation parameters were tested to find the optimal light mode as the continuous light or $12 \mathrm{~h}$ light/ $12 \mathrm{~h}$ dark cycle to maximize pigment amount. In order to determine the pigment amount in the cultivated algae extraction was done. Then by using UV spectrophotometer amount of chlorophyll $a$ and $b$ were determined in the obtained extracts.
\end{abstract}

Keywords: Microalgae, Chlorella sp., Photobioreactor design, Extraction, Pigments.

\section{Introduction}

Microalgae are an extensive group of autotrophic microorganisms, ranging from unicellular to multicellular forms. They have a higher productivity per unit area than other photosynthetic organisms like higher plants due to the fact, microalgae can produce biomass approximately 50 times faster- and have fast production cycles, fewer nutrient requirements, ability to adapt a wide range of irradiance and does not compete for land with crops [1].

Such advantages of algae lead to different studies that discover a new relevance for the wide field of application of these microorganisms as sources of future fuels, feed, food supplements, pharmaceuticals, and high-value products as well as, a way to reduce $\mathrm{CO}_{2}$ for deceleration of the global warming. Due to the limited fossil fuel sources and global warming microalgae can be used as biofuel sources. They are capable of accumulating significant amounts of lipids, especially for biofuel production [2]. Biofuels that obtained from microalgae show very similar properties to petroleum with an accumulation of lipids [3].
In known 40.00 types of microalgae Chlorella $s p$, is the most prominent species. Chlorella $s p$. cells are unicellular, spherical green algae with a cup-shaped chloroplast. Chlorella sp. are spherical cells with a diameter of 2-10 $\mu \mathrm{m}$ and similar to plants due to many structural elements [4].

Chlorella sp. are capable of photosynthesis by capturing sunlight and provide their energy in the photosynthesis process while responding to the oxygen need of the world. They take $30 \%$ of the carbon dioxide and give almost $70 \%$ of the planet's oxygen. Half of the oxygen in the atmosphere is produced by microalgae. Microalgae can live in almost any environment from frozen environments to hot desert environments. This means that microalgae can also grow in any environment and a large amount of biomass could be obtained per unit area.

Today, Chlorella sp. and Spirulina continue to be used as food supplements. Chlorella sp. cells contain $50 \%$ protein, 5\% chlorophyll, and a large amount of Bcomplex vitamins [5]. Their metabolites involve many 
active compounds that have antifungal, antitumor, antibacterial and antiviral activities.

Besides algae cultures can be used for the removal of pollutants as nitrogen and phosphorus in wastewater. They can also use to remove nitric oxide and recover heavy metals from effluents [6].

The major point in microalgal growth and metabolite production is the development of economically feasible, large-scale cultivation systems. Chlorella $s p$. can be cultivated as autotrophic, heterotrophic and mixotrophic growth. The most common way of autotrophic growth is the open pond and mainly used for large scale biomass production due to feasibility. For the heterotrophic growth, there is no need for the light source, but an organic carbon source is needed. Mixotrophic growth is the combination of both autotrophic and heterotrophic techniques. In a study done by Liu et al., effects of cultivation strategies on the cultivation of Chlorella $s p$. were investigated in photoreactors [7].

Closed photobioreactor systems have been developed to overcome some of the limiting factors of open pond growth. In photobioreactor (PBR) design, the abiotic, such as light, temperature, gases, $\mathrm{pH}$, and nutrients; biotic, such as pathogen contamination and competition with other microorganisms and operational factors have great importance. However, light is the most crucial parameter due to its control difficulties [8]. Chlorella $s p$. is resistant to harsh conditions (excessive exposure to a slight increase in temperature, nitrogen limitation, high $\mathrm{CO}_{2}$ concentration, etc.) and invaders. In a study done by Chou et al., isolation and characterization of Chlorella sp. mutants were done in order to achieve enhanced thermo- and $\mathrm{CO}_{2}$ tolerances for $\mathrm{CO}_{2}$ sequestration and utilization of flue gases [9].
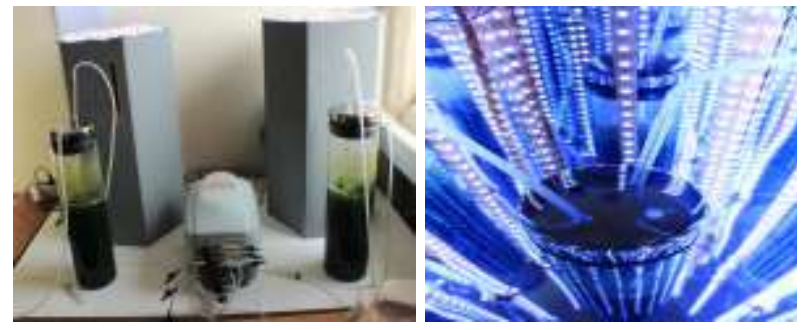

Figure 1. The pictures of designed photobioreactors; left: outside view, right: inside view.

The ideal growth of each species of algae occurs in culture medium with specific conditions. For example, Spirulina at high $\mathrm{pH}$ and bicarbonate density, Chlorella $s p$. in nutrient-rich medium, and Dunaliella salina show the best growth in very high salinity [10]. For instance, in a study done by Widayat and Wibisono waste tofu water was used to cultivate Chlorella $s p$. as an alternative source for microalgae [11].
There are many advantages of heat control to prevent contamination in the microalgae production of closed bioreactors and to ensure high production through effective use of high-intensity light. With the prevention of pollution risk, larger species can be produced, and bioreactors can be used in the external environment. It is easier to control the culture medium in closed photobioreactors. Thus, the obtained product can achieve high quality and efficiency [12]. In a study done by Granata, dependency of microalgal production on biomass and its relationship to the bioreactors were investigated [13]. And it was stated that, production of algal cultures decreases with the volume of the bioreactor, and open bioreactor systems are not as productive as closed ones.

However there are studies done to scale up to pilot plant photobioreactors. In a study done by Papapolymerou et al., were studied scaling-up sustainable Chlorella vulgaris microalgal biomass cultivation from laboratory to pilot-plant photobioreactor for biofuel purposes [14].

In a study done by Derwenkus et al., Chlorella sp.were used to extract unsaturated fatty acids and carotenoids [15]. The obtained data showed that it is possible to efficiently extract both fatty acids and carotenoids from wet microalgae by selecting suitable solvents and thus circumvent energy-intensive drying of the biomass.

In this study Chlorella sp. were cultivated in a designed bioreactor in order to determine the effect of light availability on the cell growth and pigment capacity. To achieve that two sets of experiments were carried. For the first group Chlorella sp. were exposed to the light for $24 \mathrm{~h}$ continuously. For the second group Chlorella $s p$. were exposed to the light for 12 hours period.

\section{Materials and Methods 2.1 Photobioreactor Design}

The bubble column photobioreactor system was designed in consideration of good aeration, good mass transfer characteristics, proper lighting. The volume of the reactor and working volume were chosen as $2 \mathrm{~L}$ and $1.5 \mathrm{~L}$ to consider the safety precaution. As an artificial light source, led strips with $120^{\circ}$ were chosen (Alles İthalat Led Controller,5050 SMD LED) and a hexagonal plexiglass container was designed to stick these led strips on each surface. On each surface, three led strips were assembled with equal lengths and homogeneous arrangement. The height and weight of the led container and the distance between the reactor and the led strips were taken as $50 \mathrm{~cm}, 15 \mathrm{~cm}$, and $2.5 \mathrm{~cm}$, respectively. Two proper thermal resistant glass reactors (WMF brand glass jars with stainless steel caps) were gathered. 


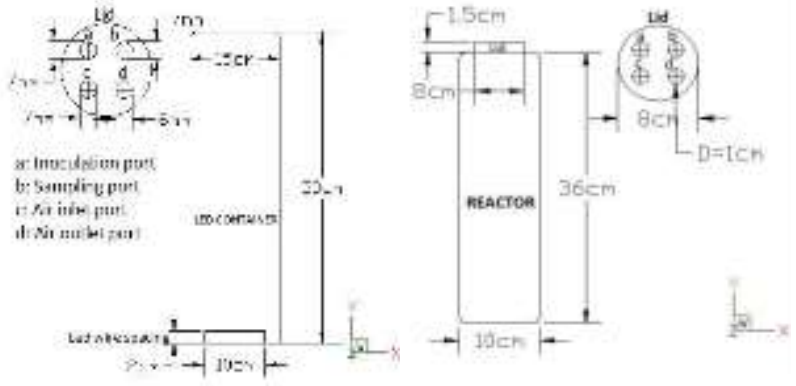

Figure 2. The AutoCAD Drawing of The Photobioreactor Design.

The distance of the light source to the reactor surface was designed as $2.5 \mathrm{~cm}$ from the edge to the led container and the reactor was bought with a diameter of $15 \mathrm{~cm}$. According to the parametric studies of Kim et al., [16], when two reactors with different diameters were used for the cultivation of algae with the same amount of light intensity, it was obtained that the growth rate decreases as the reactor diameter increase. The $\mathrm{S} / \mathrm{V}$ ratio of the reactor is another important parameter for the cultivation. Thus, the reactor was designed with consideration of these parameters.

\subsection{Microalgal Strain, Growth Medium and Culture Conditions}

Chlorella sp., which is the autotrophic microalgal strain, was cultivated in BG-11 medium in two bubble column photobioreactors. As reported in the literature, BG-11 components are $\mathrm{Fe}$-Citrate solution, citric acid, ferric ammonium citrate, $\mathrm{NaNO}_{3}, \quad \mathrm{~K}_{2} \mathrm{HPO}_{4} \cdot 3 \mathrm{H}_{2} \mathrm{O}$, $\mathrm{MgSO}_{4} \cdot 7 \mathrm{H}_{2} \mathrm{O}, \quad \mathrm{CaCl} 2.2 \mathrm{H}_{2} \mathrm{O}, \quad \mathrm{Na}_{2} \mathrm{CO}_{3}, \quad \mathrm{MgNa}_{2}-$ EDTA. $\mathrm{H}_{2} \mathrm{O}$ and trace metals solution. Trace element solution components are $\mathrm{H}_{3} \mathrm{BO}_{3}, \mathrm{MnCl}_{2} .4 \mathrm{H}_{2} \mathrm{O}$, $\mathrm{ZnSO}_{4} .7 \mathrm{H}_{2} \mathrm{O}, \quad \mathrm{CuSO}_{4} .5 \mathrm{H}_{2} \mathrm{O}, \quad \mathrm{Na}_{2} \mathrm{MoO}_{4} .2 \mathrm{H}_{2} \mathrm{O}$, $\mathrm{Co}\left(\mathrm{NO}_{3}\right)_{2} .6 \mathrm{H}_{2} \mathrm{O}$. The $\mathrm{pH}$ of $\mathrm{BG}-11$ medium was 7.4 [17]. The prepared BG-11 medium was autoclaved and then allowed to cool down.

For the cultivation, $5 \mathrm{~mL}$ of Chlorella sp. solution was inoculated to BG-11 medium in $250 \mathrm{~mL}$ erlenmayers for 24 hours, under the bulb light (Philips, E27 ES, Warm White Bulb). After observation of the strain growth, $10 \%$ inoculation was performed to $500 \mathrm{~mL}$ erlenmayers to increase the inoculum amount for the preparation of $1.5 \mathrm{~L}$ working volume. For $1.5 \mathrm{~L}$ reactor, 5\% inoculation was performed. BG-11 medium was prepared according to the recipe reported in the literature [18].

Air pump (Atman Aquarium Air Pump, HP-8000) was used for $\mathrm{CO}_{2}$ and $\mathrm{O}_{2}$ supply with a $3 \mathrm{~L} / \mathrm{min}$ aeration rate. The air was supplied by L-shaped glass pipes with a decreasing diameter at the outlet of the pipe to create smaller bubbles. Microalgae production was performed under room conditions $\left(25{ }^{\circ} \mathrm{C}\right.$ temperature- $1 \mathrm{~atm}$ pressure).

\subsection{Determination of the Growth Curve}

The algae concentration was monitored by taking $4 \mathrm{~mL}$ samples by using injectors and optical density was measured by using UV-Vis Spectrophotometer (Thermo Scientific, Genesys 10S UV-VIS Spectrophotometer) at wavelengths of $620,650,680 \mathrm{nms}$ in order to decide the optimum wavelength. The growth curve graph was obtained at $650 \mathrm{~nm}$ as an optimum wavelength. For estimation of the specific growth rate, the growth curves were plotted, and calculations were done according to the equations from Shuler and Kargi.

$$
\begin{gathered}
\frac{d_{x}}{d_{t}}=\mu_{n e t} * x \\
\ln \frac{x}{x_{0}}=\mu_{n e t} * t
\end{gathered}
$$

Since optical density is directly proportional to $\mathrm{x}$, calculations were done with optical density values.

The product yield coefficient $\left(Y_{P / X}\right)$ was calculated according to the equation from Shuler and Kargi [19]

\subsection{Estimation of the Dry Weight}

For dry weight estimation, $130 \pm 10 \mathrm{ml}$ sample was taken from each reactor for three experiments, respectively. The samples were dried in a freeze dryer (Telstar, LyoQuest) and scaled up to the $1500 \mathrm{ml}$ working volume.

\subsection{Determination of the Chlorophyll Content}

Pigment capacities were measured with spectrophotometric methods. First, a $25 \mathrm{~mL}$ sample solution was centrifuged at $5000 \mathrm{rpm}$ for $4 \mathrm{~min}$, the pellet is resuspended in a $90 \%$ acetone and dimethyl sulfoxide with a ratio of $3: 2$. After $1 \mathrm{~h}$, the solution was centrifuged under the same conditions. The supernatant was analyzed by UV-Vis spectrophotometer (Thermo Scientific, Genesys 10S UV-VIS Spectrophotometer) and Chlorophyll a, Chlorophyll b and total photoprotective carotenoid amounts were calculated according to the absorbance values and the correlations from Jeffrey and Humphrey, [20] Pottier et al., [21].

\subsection{Effect of Light Availability on the Cell Growth}

After the algae culture was obtained the effect of light availability on the cell growth was investigated. The cultivation parameters were tested to find the optimal light mode as a continuous light or $12 \mathrm{~h}$ light/ $12 \mathrm{~h}$ dark cycle to maximize pigment amount. The applied light energy was kept constant while applying either continuous or intermittent lighting during the growth of 
Celal Bayar University Journal of Science

Volume 15, Issue 4, 2019 p 377-383

Doi: $10.18466 /$ cbayarfbe. 523332

microalgae. Three sets of experiments were carried in order to determine the effect of light availability on cell growth. In the first experiment, the microalgae were ventilated with a diffuser for 24 hours under light, in the second experiment under 24 hours light without diffuser and in the third experiment by 12 hours light- 12 hours dark growth.

In Table 1, experiments and their conditions were explained.

Table 1. Experimental setups and their conditions.

\begin{tabular}{|c|c|}
\hline Experiments & Conditions \\
\hline First Experiment & $\begin{array}{c}\text { with Diffusor, 24h light, } \\
\text { room temperature }\end{array}$ \\
\hline Second Experiment & $\begin{array}{c}\text { without Diffusor, 24h } \\
\text { light, room temperature }\end{array}$ \\
\hline Third Experiment & $\begin{array}{c}\text { without Diffusor, 12h } \\
\text { light/ 12h dark, room } \\
\text { temperature }\end{array}$ \\
\hline
\end{tabular}

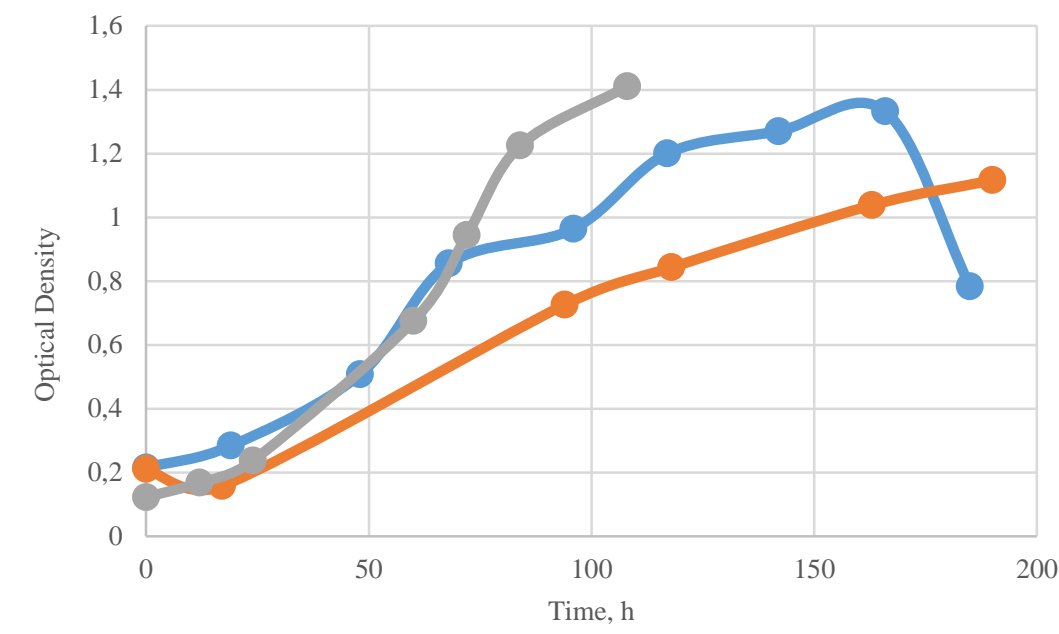

$\longrightarrow$ Experiment 1, 24 h light

Experiment 2, $24 \mathrm{~h}$ light

Experiment 3, 12h light/ $12 \mathrm{~h}$ dark cycle

But the inoculation for the second experiment was performed from the detrited cells. Thus; as is seen in the Figure 3, the slope of the first experiment with diffusor, was observed steeper than the second experiment without diffusor. The third experiment was performed under a $12 \mathrm{~h}$ dark/ $12 \mathrm{~h}$ light cycle and the growth curve was observed as steepest of all.

\begin{abstract}
In Figure 3 the growth curve of the microalgae was given. Although in the first and second experiments were performed under the same light conditions $(24 \mathrm{~h}$ full light), the difference in the growth curves was originated from the aeration problem with diffusers. After the solution of the aeration problem, the slope of the growth curve of the second experiment was expected to be steeper than the first one.

3. Results and Discussion

3.1 Growth Curve of the Microalgae
\end{abstract}

Figure 3. The growth curve of the Microalgae under different light pattern.

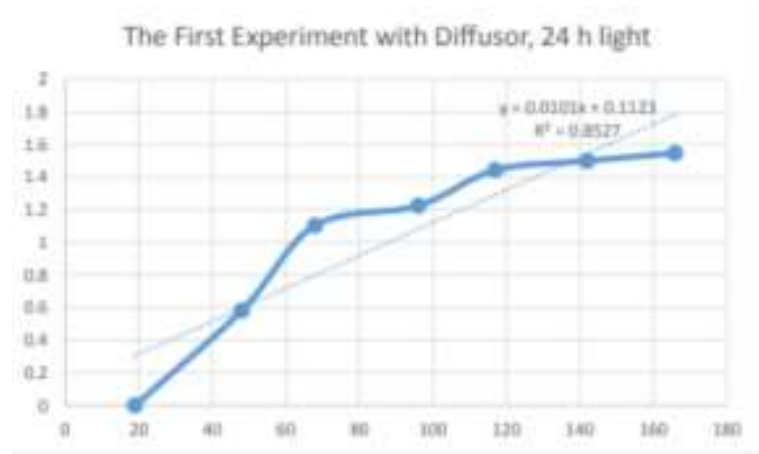

Figure 4. The specific growth rate curve for $1^{\text {st }}$ experiment.

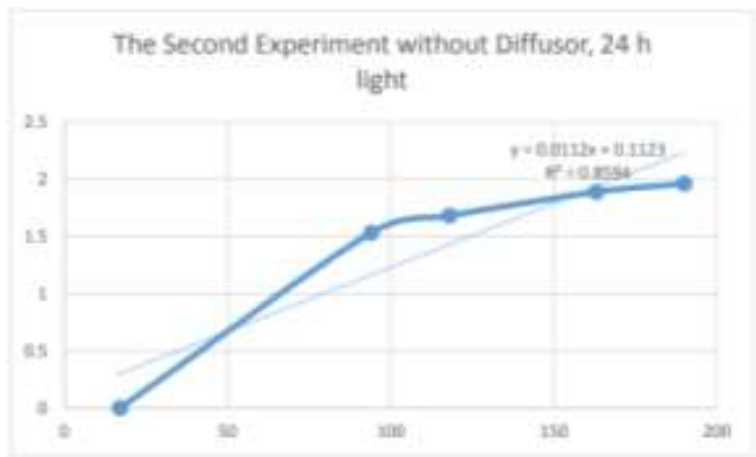

Figure 5. The specific growth rate curve for $2^{\text {nd }}$ experiment. 


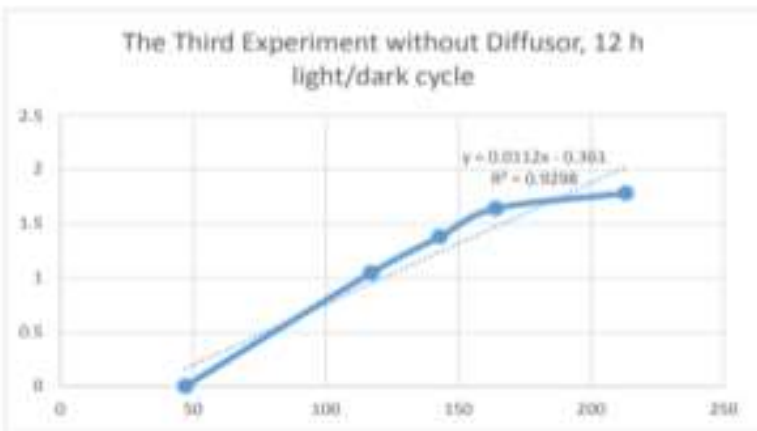

Figure 6. The specific growth rate curve for $3^{\text {rd }}$ experiment.

A ceramic diffuser, which should provide an increase in the mass transfer area of the $\mathrm{CO}_{2}$ supply, was used in the first experiment. The experiments were performed with two reactors to check the results. But, the results for each reactor of the first experiment, were not equal due to the non-standardized pore diameter of the ceramic diffusers and nonadjustable air flowrate. For the second and third experiments, the diffusor was not used, and air flowrate was able to be fixed and measured as 3 $\mathrm{L} / \mathrm{min}$. Instead of the ceramic diffusers, the glass pipes with a decreasing diameter at the outlet were used. The decreasing of the diameter at the outlet of the pipe decreased the air bubble size and increase the mass transfer area. Thus, the airflow rate and bubble size provided a good mixing in the reactor.

As a result, biofilm-forming, and algae agglomeration was not observed during the experiments.

\subsection{Specific Growth Rate of the Microalgae}

In Table 2 specific growth rates of the microalgae were given.

Table 3. Dry Weight and Pigment Capacities of Three Experiment.

\begin{tabular}{|c|c|c|c|c|c|}
\hline & $\begin{array}{c}\text { Working } \\
\text { Volume (L) }\end{array}$ & $\begin{array}{c}\text { Dry Weight } \\
\text { (mg) }\end{array}$ & & & $\mathbf{Y}_{\mathbf{P} / \mathbf{X}}$ \\
\hline \multirow{3}{*}{ Experiment 1} & \multirow{3}{*}{1.5} & \multirow{3}{*}{3751.2} & Chlorophyll a (mg/L) & 3.96 & 0.0015 \\
\hline & & & Chlorophyll b (mg/L) & 0.87 & 0.0003 \\
\hline & & & Carotenoid (mg/L) & 2.48 & 0.001 \\
\hline \multirow{3}{*}{ Experiment 2} & \multirow{3}{*}{1.5} & \multirow{3}{*}{4360.8} & Chlorophyll a (mg/L) & 8.67 & 0.0029 \\
\hline & & & Chlorophyll b (mg/L) & 2.10 & 0.0007 \\
\hline & & & Carotenoid (mg/L) & 3.30 & 0.0011 \\
\hline \multirow{3}{*}{ Experiment 3} & \multirow{3}{*}{1.5} & \multirow{3}{*}{4002.85} & Chlorophyll a (mg/L) & 15.90 & 0.0059 \\
\hline & & & Chlorophyll b (mg/L) & 2.80 & 0.001 \\
\hline & & & Carotenoid (mg/L) & 6.40 & 0.0024 \\
\hline
\end{tabular}

Table 2. Specific Growth Rate Values.

\begin{tabular}{|c|c|}
\hline & $\boldsymbol{\mu}(\mathbf{1} / \mathbf{h})$ \\
\hline $\begin{array}{c}\text { First Experiment with } \\
\text { Diffusor, 24h light }\end{array}$ & 0.0101 \\
\hline $\begin{array}{c}\text { Second Experiment } \\
\text { without Diffusor, 24h } \\
\text { light }\end{array}$ & 0.0112 \\
\hline $\begin{array}{c}\text { Third Experiment } \\
\text { without Diffusor, 12h } \\
\text { light/ 12h dark }\end{array}$ & 0.0112 \\
\hline
\end{tabular}

The specific growth rate of the second and third experiments resulted in the same and higher than the first experiment. According to this result, the aeration has great importance on cell growth. Another important parameter is the photo-limitation effect. In the studies of Kim et al. [16], while the density of the algae under a light intensity increases, the light intensity inside the reactor and the growth rate of the algae decrease because of the photo-limitation effect. According to the article, under the same mean light intensity, the specific growth rate was shown to be related to the incident light intensity on the surface of the reactor due to the photoinhibition effect caused by high amount of intensity.

\subsection{Chlorophyll Content of the Microalgae}

In Table 3 dry weight and pigment capacities of three experiments were tabulated. 
According to Table 2, the highest pigment capacity was observed in the 3rd experiment with a $12 \mathrm{~h}$ dark - $12 \mathrm{~h}$ light cycles. In the second experiment; the pigment capacity is higher than the first experiment which is expected. The aeration problem in the first experiment caused cell death. Thus, the number of living cells decreased, and the pigment capacity was obtained as smallest in the first experiment. The chlorophyll a and carotenoid amount in the third experiment, which was performed under $12 \mathrm{~h}$ light/ $12 \mathrm{~h}$ dark cycle, was doubled. The chlorophyll b amount was doubled between first and second experiments by changing aeration, but in the third experiment, the light/dark cycle caused only $24 \%$ increasing.

According to the studies, the decrease in the average light intensity inside the reactor is one of the problems in the growth of algae in photo-bioreactors. The light absorption proportionally increases with an increase in biomass, specifically in the dense cultures [6]. As a result, a more efficient way to supply light to the algae culture should be found. Between the first and second batch, fixing aeration shows the importance of an increase in dry weight.

In summary; to ensure optimum conditions in microalgae production the light source, reactor volume, distance between light source and reactor, reactor design are important parameters. In literature, it was stated that an increase in reactor diameter affects microalgae growth negatively at the same light intensity conditions. This point was taken into consideration in our reactor design. In the first and second experiments $\left(25^{\circ} \mathrm{C}\right)$ starting at room conditions, the temperature emitted by led lights was measured as $29{ }^{\circ} \mathrm{C}$ at the end of the experiment. In the third experimental setup, only $2^{\circ} \mathrm{C}$ increase was observed due to the 12 hour light cycle and 12 hour dark light cycle.In addition, the results of the first experimental design were not balanced because of the lack of air flow with ceramic diffusers. In the second and third experimental apparatus, a good mixture was obtained by using glass tubes that narrowed at the air flow outlet. As a result, microalgae accumulation and biofilm formation were not observed. In the first and second experiments, although the light conditions (full light for 24 hours) were the same, the difference in growth curves was due to ventilation. According to these results, ventilation is important for the growth of algae.

\section{Conclusion}

In conclusion, it was seen that the BG-11 medium has enough nutrients for sufficient growth of the algae cultivation. After fixing the flow rate of air to $3 \mathrm{~L} / \mathrm{min}$, the increase in the growth of the Chlorella $s p$. cells was observed, clearly.
With comparison to the pigment concentrations of the two setups, it was observed that $12 \mathrm{~h}$ light/12 h dark cycle is more efficient than $24 \mathrm{~h}$ light cycles. The light intensity has great importance which influences photosynthetic activity, thus the specific growth rate.

The concentrations of Chlorophyll-a and Carotenoid were doubled in the $12 \mathrm{~h}$ light/12 $\mathrm{h}$ dark cycle. Moreover, photo-inhibition is another critical point based on the high density of light. The photo-limitation effect was observed in the experiments as high cell density which causes a low specific growth rate.

\section{Ethics}

There are no ethical issues after the publication of this manuscript.

\section{References}

1. Brasier, M. D., Green, O. R., Jephcoat, A. P., Kleppe, A. K., Van Kranendonk, M. J., Lindsay, J. F., ... \& Grassineau, N. V. 2002. Questioning the evidence for Earth's oldest fossils. Nature, 416(6876), 76

2. Converti, A., Casazza, A. A., Ortiz, E. Y., Perego, P., \& Del Borghi, M. 2009. Effect of temperature and nitrogen concentration on the growth and lipid content of Nannochloropsis oculata and Chlorella vulgaris for biodiesel production. Chemical Engineering and Processing: Process Intensification, 48(6), 1146-1151.

3. González-Fernández, C., Sialve, B., Bernet, N., \& Steyer, J. P. 2012. Impact of microalgae characteristics on their conversion to biofuel. Part I: Focus on cultivation and biofuel production. Biofuels, Bioproducts and Biorefining, 6(1), 105-113.

4. Safi, C., Zebib, B., Merah, O., Pontalier, P. Y., \& Vaca-Garcia, C. 2014. Morphology, composition, production, processing and applications of Chlorella vulgaris: a review. Renewable and Sustainable Energy Reviews, 35, 265-278.

5. Lee, R., Phycology. Cambridge [England]: Cambridge University Press., 4th ed., 1999, pp.213-217.

6. Abu-Ghosh, S., Fixler, D., Dubinsky, Z. and Iluz, D. 2015. Continuous background light significantly increases flashing-light enhancement of photosynthesis and growth of microalgae. Bioresource Technology, 187, 144-148.

7. Liu, X., Hong, Y., Liu, P. Zhan, J., Yan, R., 2019. Effects of cultivation strategies on the cultivation of Chlorella sp. HQ in photoreactors Frontiers of Environmental Science and Engineering 13: $781-11$

8. Carvalho, A., Silva, S., Baptista, J. and Malcata, F. 2010. Light requirements in microalgal photobioreactors: an overview of biophotonic aspects. Applied Microbiology Biotechnology, 89(5), $1275-1288$

9. Chou, H., Su, H., Song, X. 2019. Isolation and characterization of Chlorella sp. mutants with enhanced thermo- and $\mathrm{CO} 2$ tolerances for $\mathrm{CO} 2$ sequestration and utilization of flue gases. Biotechnology for Biofuels 12, 251.

10. Yılmaz, H. K. 2006. Mikroalg Üretimi için Fotobiyoreaktör Tasarımları. EÜ Su Ürünleri Dergisi, 23(1/2), 327-332.

11. Widayat, J.P. and Wibisono J., 2018. Cultivation of Microalgae Chlorella $s p$ on Fresh Water and Waste Water of Tofu Industry. The 2nd International Conference on Energy, Environmental and Information System (ICENIS 2017), 31, 1-3. 
12. Walker, T. L., Purton, S., Becker, D. K., \& Collet, C. 2005. Microalgae as bioreactors. Plant cell reports, 24(11), 629-641.

13. Granata, T., 2017. Dependency of Microalgal Production on Biomass and the Relationship to Yield and Bioreactor Scale-up for Biofuels: a Statistical Analysis of 60+ Years of Algal Bioreactor Data. BioEnergy Research, 10 (1), 267-287.

14. Papapolymerou, G., Karayannis, V., Besios, A., Riga, A. Gougoulias, N., Spiliotis, X., 2019. Scaling-up sustainable Chlorella vulgaris microalgal biomass cultivation from laboratory to pilot-plant photobioreactor, towards biofuel. Global NEST Journal, 21, No , 37 42 .

15. Derwenkus, F., Metz, F., Gille, A., Schmid-Staiger, U., Briviba, K., Schliessmann U., Hirth, T., 2019. Pressurized extraction of unsaturated fatty acids and carotenoids from wet Chlorella vulgaris and Phaeodactylum tricornutum biomass using subcritical liquids. Global Change Biology, Bioenergy, 11, 335-344.
16. Kim, J., Lee, J. and Lu, T. 2015. A model for autotrophic growth of Chlorella vulgaris under photolimitation and photoinhibition in cylindrical photobioreactor. Biochemical Engineering Journal, 99, 55-

17. Andersen, R. A. (Ed.). 2005. Algal culturing techniques. Elsevier. 18. ATCC Medium: 616 Medium BG-11 for Blue-green Algae, www.atcc.org

19. Shuler, M. and Kargi, F., Bioprocess engineering. Upper Saddle River, NJ: Prentice Hall 2002.

20. Jeffrey, S.W., Humphrey, G.F. 1975. New spectrophotometric equations for determining chlorophyll a, b, c1 and c2 in higher plants, algae and natural phytoplankton. Journal of Plant Biochemistry Physiology, 167, 191-194.

21. Pottier, L., Pruvost, J., Deremetz, J., Cornet, J., Legrand, J. and Dussap, C. 2005. A fully predictive model for one-dimensional ligh attenuation by Chlamydomonas reinhardtii in a torus photobioreactor. Biotechnology and Bioengineering, 91(5), 569-582. 